\title{
The Ethical Decision-making of Sport Athletes and Its Environmental Factors
}

\author{
Dayoun Lim \& Sungjoo Park* \\ Kookmin University
}

\begin{abstract}
[Purpose] Based on Haidt's social-intuitionist theory, this study analyzes the differences in ethical decision-making between sport athletes and the general public in order to understand the ethical judgment tendencies of athletes and examine the determining factors influencing their judgment from the perspective of their environment. In so doing, this study hopes to motivate education for enhancing ethical consciousness as well as institutional policy. [Methods] To this end, 200 elite athletes in their twenties registered for more than 10 years at the Korean Sports Association and 200 college students in their twenties from five universities in Seoul were selected for comparison. Response trends for each item were analyzed by percentage, and differences between groups were confirmed by the $x^{2}$ test method. [Results] The results are as follows. First, in general ethical situations, athletes usually showed a compulsory ethical view that emphasized principles, whereas in a sports situation, they showed a double consciousness and revealed a very strong consequential ethical view which put much emphasis on outcome. Second, athletes strongly maintained a Confucian ethical view that recognized ethics as a norm compared to the general public and, as a result, it was found that paternalism was relatively stronger than rationalism in their ethical decision making. Third, athletes regarded other people's thoughts and group interests as important criteria for ethical decision-making rather than individual thoughts and interests, and showed a group-centered mindset which emphasized group harmony and relationship. Fourth, while the general public viewed excellent athletes as those with excellent skills and good personality, and valued their morality, athletes thought relatively little of the influence and importance of morality in their success. Finally, it was found that coaches and managers were fundamental to the formation of the athlete's moral view. [Conclusion] An in-depth understanding of sports participants' ethical awareness should come first in order to enhance ethical consciousness in sport. I hope this study will work as a catalyst for research which approaches athletes' ethical consciousness from a socio-cultural context.
\end{abstract}

Key words: Sport Athletes, Ethical Decision-making, Ethical Consciousness, Reasoning, Intuition.

\section{서 론}

$\mathrm{P}$ 는 재능 있고 성실한 대학 축구선수이다. $\mathrm{P}$ 는 어릴 적부

논문 투고일 : 2021.01.29.

논문 수정일 : 2021.03.16.

게재 확정일 : 2021.03.20.

* 교신저자 : 박성주(sjpark54@kookmin.ac.kr).
터 정직을 강조하는 가정환경에서 자라왔다. 이러한 부모님 의 가정교육 덕분에, $\mathrm{P}$ 는 어떠한 경우라도 거짓말 하는 것은 나쁜 행위라고 여긴다. $\mathrm{P}$ 의 팀은 리그 챔피언 결정전에 진출 했다. 이 결승전은 감독의 재계약, 선수들의 프로입단, 팀의 재정지원 문제에 있어 무척이나 중요한 경기이기에 모든 선 수들이 최선을 다해 뛰었다. 결승전답게 양 팀이 0:0으로 팽 팽히 맞서고 있는 상황이다. 후반전 종료 5 분을 남겨둔 가운 
데 동료 선수의 절묘한 패스를 받은 P는 상대팀 페널티 에어 리어 안까지 공을 몰고 가다 상대 수비수에게 걸렸는지 골문 앞에서 넘어졌다. 뒤에서 달려오던 심판은 이 장면을 목격 하고 길게 호각을 불었다. 상대 팀 선수들은 심판에게 몰려 들어 다리에 걸려 넘어진 게 아니라고 항의했으나, 심판은 단호하게 페널티킥을 선언했다. $\mathrm{P}$ 의 팀 동료선수들과 코치 진, 그리고 팬들은 환호성을 질렀다. 하지만 $\mathrm{P}$ 는 고민을 한 다. 왜냐하면 사실 상대 수비수의 다리에 걸려 넘어진 것이 아니라 순간적으로 자신의 다리가 꼬여 스스로 넘어진 것이 기 때문이다. $\mathrm{P}$ 는 심판에게 다가가 솔직히 상대 수비수의 반 칙이 아니라 스스로 넘어진 것이라 말을 하며 판정을 번복해 달라고 요청했다. 심판의 페널티킥 판정은 번복되었고 이 경기는 승부차기 끝에 $\mathrm{P}$ 팀의 패배로 종료되었다. 경기가 끝 난 후, 모든 코치진과 선수들이 $\mathrm{P}$ 를 원망하는 표정으로 모여 있다. 감독이 $\mathrm{P}$ 선수에게 왜 판정을 번복했냐고 물었다. $\mathrm{P}$ 는 "어떤 경우라도 정직해야 한다고 학교에서 배웠습니다"라 고 답했다. 이에 감독은, "여긴 학교가 아니라 축구 경기장 이야”라고 말하며 $\mathrm{P}$ 의 이기적이고 동료에 대한 배려 없는 결정을 질책했다. $\mathrm{P}$ 는 자신의 '정직한' 결정에 대한 잘못을 인정하고 코치진과 동료들에게 사과했다.

어떤 문화에서 좋은 행동으로 여겨지는 것이 다른 문화에 서는 잘못된 행동으로 받아들여지는 경우들이 있다. 그렇다 면, 스포츠는 우리사회의 문화와 관습을 반영하는 것일까, 아니면 독립적인 문화와 관습을 가진 것일까? 일반 사회에 서 $\mathrm{P}$ 의 행위와 스포츠 속 $\mathrm{P}$ 의 행위에 대한 도덕적 평가는 달 라야 하는 것일까? 만약 그렇다면 그 근거는 무엇일까? 위의 $\mathrm{P}$ 사례처럼 스포츠선수의 윤리적 의사결정에는 이중적 구조 가 존재한다. 달리 말해, 스포츠는 공정성을 중시여기면서 도 불공정한 관행에 노출되어 있는 이중성이 드러난다. 가 령 스포츠선수들은 규칙을 지키는 것이 스포츠선수로서 가 장 중요한 덕목이라고 여기면서도, 규칙과 인정(人情)의 가 치가 충돌하는 상황에서는 규칙보다는 인정(의리)을 우선시 하는 경향을 보인다. 국내 스포츠계에서 발생하는 대부분의 승부조작 사건이 이러한 경우이다. 스포츠선수들의 의사결 정에는 어떠한 요인들이 크게 영향을 미치는 것일까?

우리는 살아가면서 수많은 선택과 결정을 한다. 이러한 선택과 결정의 상황에서, 특히 윤리적 상황에서의 개인의 판 단은 어떤 과정과 작용을 통해 내려지는 것일까? 윤리적 판 단에 영향을 주는 요인은 여러 가지가 있지만 크게 성격, 인 지적 발달 등과 같은 개인적 특성과 자신이 속한 사회나 조직
의 윤리적 분위기, 기풍과 같은 환경적 특성, 이 두 가지 차원 으로 구분할 수 있다(Moon, 2019). 개인적 특성을 중요시 하는 입장의 대표적인 학자는 Kant의 사상을 배경으로 개인 의 도덕성 발달을 강조하는 Lawrence Kolhberg이고, 환 경적 특성을 중요시하는 입장의 대표적인 학자는 Hume의 경험론적 철학을 배경으로 도덕성의 사회문화적 측면을 강 조하는 Jonathan Haidt를 들 수 있다(Kang, 2015).

최근 개인의 윤리적 의사결정은 그가 속한 사회의 윤리적 분위기나 문화적 관습에 의해 직접적인 영향을 받는다는 사 실을 입증하는 연구들이 증가되고 있다(Brass, Butterfield, \& Skaggs, 1998; Caldwell \& Moberg, 2007; Koop, 2013; Oyserman \& Lee, 2008; Shin, 2015; Young \& Durwin, 2013). 일찍이 Durkheim(1895/2019)은 아리 스토텔레스(Aristotle) 철학의 영향을 받아 인간의 도덕성 은 사회적으로 만들어지고 규정된 본질이라고 보았다. 미국 의 신학자이자 철학자인 Niebuhr(2013)도 그의 저서 『Moral Man and Immoral Society(도덕적 인간과 비도 덕적 사회)』를 통해 개인의 도덕성만으로 사회정의를 실현 할 수 없다며 사회윤리의 중요성을 강조하였다. 심리학자 Lauren Slater(2004) 또한 그녀의 저서 『Opening Skinner's Box(스키너의 심리상자 열기)』에서 "한 개인의 도덕적이거나 비도덕적인 행동이 고정된 성격적 특성 때문 이라고 생각하지 않는다. 그것은 그가 언제, 어디서, 누구와 함께 있는가가 훨씬 더 중요하다"(p. 70)고 말한 사회심리 학자 Lee Ross의 주장을 인용하며 인간의 행동은 기후나 바람처럼 변하는 외적 영향력에 의해 좌우됨을 강조한다. 요컨대, 구성원 개개인이 도덕적이지 못한 것은 그 개인이 소속된 사회가 도덕적이지 못하다는 것의 방증이라는 의미 이다. 이처럼 어떤 윤리적 행동에 대한 평가는 개인이 가진 도덕적 가치와 태도에 기초하고, 이러한 가치와 태도는 개 인이 속한 사회나 문화에 지대한 영향을 받기에 두 가지 측 면 모두에 대한 검토가 필요하다.

오늘날 스포츠에서는 다양하고 복잡한 윤리적 문제들이 발생하며 스포츠선수들은 매 순간마다 윤리적 결정을 내려 야 하는 상황에 직면하게 된다. 이러한 윤리적 결정의 상황 에 있어 스포츠선수 개인의 윤리의식은 중요하게 작용할 수 밖에 없다. 윤리의식이란 윤리적 상황에 직면했을 때 문제 해결을 위해 행위자 스스로가 판단하고 행동하는데 작동하 는 도덕적 인식이나 의지, 신념, 가치, 태도를 의미한다. 스 포츠계의 사건, 사고가 터질 때마다 항상 스포츠계의 도덕 
적 해이나 윤리성 부재를 지적하며 스포츠계의 윤리의식을 저평가한다. 하지만 대중 매체에 언급되는 스포츠선수의 음 주운전, 불법도박, 승부조작, 폭력이나 성폭력과 같은 실제 드러난 사건의 통계적 자료를 통해서만 스포츠계의 윤리의 식을 평가하는 것은 단순한 진단법이다. 스포츠계의 윤리의 식을 보다 정확하게 진단하기 위해서는 스포츠라는 공동체 속의 윤리적 규범이나 기준이 스포츠선수들에게 어떻게 작 동되고 있는지에 대한 평가도 수반되어야 한다. 달리 말해, 어떤 한 집단 구성원의 윤리의식 수준에 대한 평가는 실제 윤리적 행동으로 드러난 경험적 통계와 더불어 그 집단의 도 덕규범 자체의 정당성에 대한 선험적 논의도 요구된다(Oh, Doh, Park, \& Chu, 2001).

그렇다면 스포츠선수의 윤리적 의사결정에 영향을 미치는 특별한 요인들이 존재하는 것일까? 스포츠 속 규범이나 관습 은 스포츠선수의 윤리의식 형성에 영향을 미치는 것일까? 스 포츠선수의 윤리적 판단에는 이성적인 심사숙고의 과정이 크 게 작용하는 것일까, 아니면 경험이나 정서적 직관이 더 큰 영향을 미치는 것일까? 그러한 스포츠선수의 도덕적 직관은 어떻게 형성되는 것일까? 본 논문은 바로 이러한 질문에 대한 하나의 설득력 있는 답변을 찾고자 하는 노력의 소산이라 할 수 있다. 최근 스포츠선수의 윤리의식을 강조하는 분위기와 더불어 체육단체나 유관 기관에서 실시하는 스포츠윤리교육 역시 주목을 받고는 있지만, 아직까지 스포츠선수의 윤리적 판단에 영향을 미치는 개인적 변인과 상황적 특성에 관한 담 론과 논의는 부족한 듯 보인다. 더욱이 스포츠선수의 윤리적 판단 성향 및 수준, 혹은 그것에 영향을 미치는 요인을 탐색 한 연구는 거의 없는 실정이다. 이에 본 연구는 스포츠선수의 윤리의식을 일반인과 비교하여 분석함으로써 스포츠선수의 윤리적 판단 성향을 이해하고 판단에 영향을 미치는 요인을 환경적 특성 측면에서 고찰하고자 한다. 이를 통해 스포츠선 수의 윤리의식을 제고할 수 있는 교육의 방향과 제도적 방안 마련에 대한 시사점을 제공하는 데 연구의 목적이 있다.

\section{이론적 배경 및 연구 방법}

어떤 주어진 상황에서 판단을 내릴 때, 문제의 옳고 그름 에 대해 논리적인 사고의 과정을 거쳐 판단을 내리기도 하지 만, 또한 직관에 의해 판단이 즉각적으로 이루어지기도 한 다. 직관(intuition)은 논리적 추론(reasoning)의 작용을
거치지 않고 즉각적인 사고에 의해 상황을 파악하는 것을 일 컫는데, 직접적이고 자동적인 사고과정으로 주로 신속한 판 단을 가능하게 하는 강한 신념으로 나타난다(Lee, 2017). 최근 인간의 윤리적 의사결정은 추론보다는 직관에 의존하 는 경우가 많다는 도덕심리학 연구들이 주목을 받고 있다 (Greene, 2014; Haidt, 2001, 2007, 2008, 2012; Haidt \& Graham, 2007; Lapsley \& Power, 2005; Lieberman, 2000; Narvaez, 2010, 2014). 그 대표적인 연구로 윤리적 판단은 즉각적인 정서적 반응과 함께 직관의 결과물이라고 주장한 Haidt의 사회적 직관주의 이론(social-intuitionist theory)을 들 수 있다.

Haidt의 연구에 많은 영향을 미친 Damasio(1994)는 뇌의 복내측 전전두엽 피질에 손상을 입은 환자들을 대상으 로 한 실험을 통해 정서적 직감이나 감정이 인간의 판단에 있 어 중요한 역할을 한다는 것을 뇌 과학적 측면에서 규명했다. Blair(1995) 또한 연민, 공감과 같은 정서적 직관이 인간의 윤리적 의사결정에 있어 결정적인 역할을 한다고 주장하며, 이를 증명하는 다양한 실험연구들을 제시하였다. 심리학자 인 Kuhn(1991)도 그녀의 저서 『The Skills of Argument』 에서 인간의 판단에 대한 메커니즘을 심리학적 측면에서 상 세히 설명하고 있는데, 그녀는 인간의 판단이 정서적 직관에 의존하고 있으며 판단이 이루어진 후에는 자신의 판단에 반 대되는 증거들이 제시된다 하더라도 직관을 수정하지 않는 확증편향(confirmation bias)의 경향이 있다고 주장한다.

Haidt(2001, 2007, 2008, 2012)는 실행한 다양한 윤리 적 딜레마 실험에서 사람들이 특정 판단을 내린 후, 왜 그런 판단을 내렸는가에 대한 적절한 대답을 하지 못하거나 정당 화하기에 급급하다는 사실을 발견하고, 대부분의 경우 사람 들은 별다른 숙고의 과정 없이 그들의 정서적 직관이 윤리적 판단을 즉각적으로 내리게 한다고 주장한다. 그의 사회적 직관주의 모델에 따르면, 우리가 마주한 윤리적 상황에서 내리는 판단은 감정에 크게 영향을 받으며 즉각적이고 직관 적인 형태로 도출되고, 그 이후에 의식적인 추론이 발생하 며 이때 추론은 직관에 의해 도출된 판단에 대해 합리화하는 기능을 수행할 뿐이라고 주장한다(Haidt, 2008, 2012). 그 는 우리가 어떤 상황에 직면했을 때, 그 상황이 윤리적 상황 인지 인식하고, 무엇이 옳고 그른 것인지 기준을 적용하고, 특정 판단을 내리게 하는 것은 그 상황에 직면하기 이전까지 우리가 쌓아온 사회문화적 경험이나 관습들을 통해 내재화 된 규범에 크게 영향을 받는다고 강조한다(Haidt, 2001, 
2012). 즉, 개인의 정서적 직관이 윤리적 의사결정에 결정 적인 영향을 미치고, 이 정서적 직관은 개인이 경험하는 문 화적 맥락에 기반한다는 점을 역설하였다(Yang, 2016).

이처럼 윤리적 판단이란 것은 우리가 생각하는 만큼 심사 숙고의 과정을 거치지 않으며 별다른 노력을 기울이지 않은 채 직관에 의해 자동적이고 즉각적으로 내려지는 경향이 있 다. 즉, 우리가 가진 직관은 강한 윤리적 신념으로 나타나며 윤리적 의사결정에 있어 막대한 영향을 미친다. 그렇다면 이러한 직관은 어떻게 형성되는 것일까? 직관은 개인이 소 속된 사회나 조직의 문화 속에서 반복적인 경험을 통해 형성 된다(Haidt, 2007, 2012; Lieberman, 2000; Narvaez, 2014). 즉, 자신이 반복적으로 경험하는 것에 대해 익숙해 지고, 익숙한 것을 직관적으로 선호하고 그렇지 않은 것을 배제하는 성향을 갖게 된다(Kahneman, 2011; Narvaez, 2010; Zajonc, 1980). 그렇기 때문에 직관에 의한 판단은 분석적 사고가 할 수 없는 통찰을 줄 수도 있지만, 자신의 판 단에 대한 과정을 논리적으로 설명하지 못하거나 상황에 따 라 판단이 쉽게 변할 수 있으며 편향성과 오류의 가능성이 존재한다(Lee, 2017). 따라서 바람직한 윤리적 판단을 위해 서는 개인의 정서적 직관이 추론적인 사고를 통해 검토될 필 요가 있음을 인식해야 한다(Lee, 2017).

그렇다면 스포츠 경험은 선수들의 직관 형성에 영향을 미치는 것일까? Arnold(1997)는 MacIntyre(1984)의 이론을 바탕으로 스포츠를 하나의 문화이며 그 속에 다양한 가치가 내재된 사회적으로 구조화된 '실천전통(practice)' 의 개념으로 설명한다. 스포츠선수는 스포츠의 다양한 가치 들을 반복적으로 경험하고 실천하며, 스포츠 속 보상과 벌 의 심리기제를 통해 특정 행동이 촉진되거나 통제됨으로써 특정 가치관이나 신념의 내면화가 이루어진다(Park \& Im, 2011). 따라서 스포츠선수의 도덕적 직관은 스포츠 속 경험 의 내면화를 통해 형성될 수 있을 것이다. 이런 이유 때문에, Carr(1998)는 스포츠 경험이 오히려 선수들의 비도덕적인 성향, 믿음, 태도를 형성하는 데 이바지한다고 주장한다. Shields와 Bredemeier(1995)는 승리추구를 위한 치열한 경쟁을 반복적으로 경험하는 스포츠선수들은 승부욕, 목표 지향성, 공격성, 욕심 등의 성향이 일반인들 보다 훨씬 높게 나타난다는 연구결과를 내어놓았다. Sage $(1988,1990)$ 또 한 스포츠선수들은 ‘승리’라는 최종 목표에 높은 가치를 두 고 있기에 윤리적 딜레마 상황에서 의무론적 입장 보다는 결 과론적 입장을 주로 취한다고 밝히고 있다.
본고는 개인의 윤리적 판단에 있어 추론보다 사회문화적 영향이 더 중요하다고 주장한 $\operatorname{Haidt}(2001,2007,2008$, 2012)의 '사회적 직관주의'를 이론적 토대로 스포츠선수의 윤리적 판단에 작용하는 직관의 영향을 고찰하고자 한다. 만 약 스포츠 경험이 선수들의 도덕적 직관에 영향을 미친다면 스포츠선수와 일반인의 윤리의식에는 차이가 나타날 것이 고, 이러한 차이가 무엇을 의미하는지에 대해 분석해 보고자 한다. 이를 위해, 본 연구는 대한체육회에 10 년 이상 운동선 수로 등록된 20대 엘리트선수 200명과 서울에 소재하고 있 는 5개 대학교에서 200명의 20대 대학생을 비교 대상으로 선정하였다. 윤리의식은 개인윤리와 사회윤리로 구분하여 연구자가 제작한 질문지를 통해 조사되었다. 설문문항은 연 구자가 사전에 제작한 29 개의 예비문항을 토대로 교육학, 윤리교육, 스포츠철학 전공 교수 6 명의 집중적인 검토를 거 쳐 확정된 16 개의 문항으로 구성되어 있다. 문항별 반응경 향은 백분율을 통해서 분석되었으며, 집단 간 차이는 $\chi^{2}$ 검 정방법을 통해서 확인하였다.

또한 이 연구에서는 심층면담을 통한 질적 데이터를 수집 하기 위하여 윤리적 딜레마 상황을 애니메이션 동영상으로 제작하였으며, 이와 관련된 개방형 질문을 바탕으로 심층면 담을 진행하였다. 스포츠선수의 윤리적 판단 성향과 변인을 탐색하기 위한 방법으로 일반적인 개방형 질문만으로는 연구 참여자가 딜레마 상황을 추상적으로 느끼거나 공감하지 못할 수 있다. 이에 애니메이션 영상을 사용하여 구체적이고 생생 한 맥락을 제공해줌으로써 연구 참여자가 질문의 의도를 보 다 쉽게 이해하고 상황에 몰입할 수 있도록 하였다. 질적 데 이터 자료 수집은 엘리트선수 8명을 대상으로 2020년 10월 부터 12 월까지 진행되었다. 본 연구에서는 윤리의식에 대한 스포츠선수와 일반인의 기술적 비교에 주안점을 두었다.

Table 1. Characteristics of Research Participants

\begin{tabular}{ccccc}
\hline \hline & Name & Gender & $\begin{array}{c}\text { Length } \\
\text { of career }\end{array}$ & Sports \\
\hline 1 & A & W & 16 & Swimming \\
\hline 2 & B & M & 14 & Soccer \\
\hline 3 & C & M & 15 & Volleyball \\
\hline 4 & D & M & 20 & Track \& Field \\
\hline 5 & E & W & 11 & Triathlon \\
\hline 6 & F & W & 18 & Taekwondo \\
\hline 7 & G & M & 12 & Fencing \\
\hline 8 & H & M & 17 & Basketball \\
\hline \hline
\end{tabular}




\section{스포츠선수의 윤리적 판단에 관한 고찰}

윤리적 의사결정에 있어 스포츠선수는 원칙과 결과 중 어 느 것을 우선시 하는지 알아보기 위하여 다음과 같은 상황을 제시하고 질문하였다.

당신은 학교에 가던 중 길 위에 떨어진 10 만 원을 주웠다. 학교에 도착하면 교내 분실물센터에 가져다 줄 생각으로 일 단 주운 10 만 원을 주머니에 넣었다. 학교로 향하던 도중 몸 이 불편한 할머니와 함께 어린 아이가 당신에게 구걸을 해왔 다. 할머니가 아프셔서 병원비를 급히 구해야 한다며 어린 아 이가 당신에게 도와달라고 부탁한다. 당신은 주머니 속 10 만 원을 만지작거린다. 당신은 할머니의 병원비에 사용하라고 주운 10 만 원을 어린 아이에게 줄 것인가?

이 질문에 대해 일반인의 $61.3 \%$ 가 불쌍한 아이에게 10 만 원을 주겠다고 답하며 원칙보다는 결과적인 측면을 더 지 향하는 양상을 보였다. 반면, 스포츠선수는 37.3\%만이 주 운 돈을 아이에게 주겠다고 답하며, 윤리적 판단 기준에 있 어 결과보다는 원칙을 더 중요하게 생각하는 것으로 나타났 다. 추가적인 질문에서도 비슷한 결과가 나왔는데, "친구를 돕기 위한 의도였지만 결과적으로 누군가를 속인 결과를 가 져왔다면 그 행위에 도덕적 책임을 져야 하는가?”라는 문항 에 대해 일반인의 $62.7 \%$ 가 '그렇다'라고 답하였고, 스포츠 선수는 88\%가 '그렇다'라고 답하며 윤리적 문제에 있어 일 반인보다 의무론적 윤리관을 지지하는 성향이 높음을 확인 할 수 있었다.

그러나 흥미로운 점은 "팀의 승리를 가져온다면 심판을 속일 수 있다”라는 추가질문에 대해 일반인의 39.5\%가 '그 렇다'라고 답하며 앞선 문항들과 비슷한 수치로 의무론적 윤리관을 지지하는 것으로 나타났지만, 스포츠선수는 $81.3 \%$ 가 '그렇다'라고 답하며 앞선 일반적인 상황과 달리 스포츠상황에서는 압도적으로 결과론적인 윤리관을 지지하 는 입장으로 바뀐다는 점에서 스포츠선수의 윤리의식에 이 중적 구조를 발견할 수 있었다. 달리 말해, 스포츠선수는 일 반적인 상황에서는 원칙을 중요하게 여기면서도, 스포츠상 황에서는 직관적으로 결과를 우선시 하는 경향을 보인다. 앞선 심판의 오판에 의한 페널티킥 사례에 대해 선수들은 다 음과 같이 답했다.

“그것도 하나의 실력이에요. ‘헐리우드 액션’이라고... 만약 상대편
이 그렇게 해도 선수들끼리는 충분히 이해해요. 이런 경우는 그냥 우 리 팀에 운이 따른다고 생각하는 거죠. 심판의 오심이지, 우리가 거 짓말을 하는 거라고 생각하지는 않아요. 헐리우드 액션을 잘하는 선 수들도 있지만 또 하고 싶어도 못하는 선수들도 실제로 많아요. 헐리 우드 액션 했는데 걸리면 옐로카드 받거든요. 안 걸리게 심판을 속이 는 것도 그 선수가 지닌 좋은 기술이라고 생각해요" (축구선수, B).

“축구는 단체경기잖아요. 단지 나의 선택으로 인해 팀워크가 무너 지게 할 수는 없잖아요. 이 상황에서는 당연히 페널티킥을 차는 게 맞다고 생각해요. 승패가 좌우되는 중요한 순간이고, 나뿐만 아니 라 동료선수들에게 이 경기는 많은 것이 걸려있는 중요한 시합이잖 아요. 나 혼자 착한 척 하자고 팀 전체에 피해를 끼치는 것은 너무 이 기적인 것 같아요. 그리고 무엇보다 스포츠는 원래 속고 속이는 거 아니에요? 속임수도 일종의 전략이라고 봐야죠." (농구선수, $\mathrm{H}$ ).

다음으로 "스승의 지시는 부당하더라도 어쩔 수 없이 따른다”라는 문항을 제시하였다. 이에 일반인은 $43.7 \%$, 스포츠선수는 $62.3 \%$ 가 '그렇다'라고 답했다. 이는 스포 츠선수 집단이 여전히 유교적 윤리관을 더욱 강하게 견 지하고 있으며 집단 내 권위를 중요한 기준으로 인식하 고 있는 것으로 해석된다. 또한 "동료에게 거짓말 하는 것은 다른 모르는 사람에게 거짓말 하는 것보다 더 나쁘 다"라는 문항에 대해서는 스포츠선수의 $82.4 \%$ 가 '그렇 다'라고 답하며 윤리적 의사결정에 있어 온정주의 관계 가 강하게 영향을 미치는 반면, 일반인은 $52 \%$ 만이 '그렇 다'로 답하며 가까운 사람과 모르는 사람의 도덕적 차이 를 상대적으로 크게 두지 않는 것으로 나타났다. 윤리학 의 가장 근본적 쟁점인 도덕성의 정당화 문제를 알아보 기 위해 "우리는 왜 도덕적으로 행동해야 한다고 생각하 십니까?”라는 질문에, 일반인의 $63.5 \%$ 가 “공동체가 함 께 잘 살아가기 위해서’라고 답변한 반면, 스포츠선수의 $72 \%$ 는 '인간의 당연한 도리’라는 이유를 제시했다. 이 문항을 통하여 스포츠선수 집단이 일반인보다 유교적 가 치관의 영향력을 더 크게 받고 있음을 재차 확인할 수 있 었는데, 스포츠선수들은 도덕성을 당위규범이나 마땅한 의무로서 인식하는 유교적 윤리관을 강하게 견지하고 있 는 것으로 보인다. 요컨대, 일반인의 윤리적 판단에는 합 리주의가 비교적 크게 작용하고 있지만 스포츠선수 집단 은 상대적으로 인정주의가 강하게 작용하고 있고, 또한 유교적 가치관이 스포츠선수의 사유구조와 행동양식에 많은 영향을 미치고 있는 것으로 분석된다. 
$A$ 팀은 강력한 우승 후보인 만큼 무난히 4강 진출을 확정지었다. 8 강전 마지막 경기를 앞둔 $A$ 팀은 여유 있 게 경기를 준비하고 있다. 반면 $A$ 팀의 8 강전 상대인 $B$ 팀은 이번 대회 4 강 진출에 실패하면, 팀 자체가 해체 된다는 소문이 퍼졌다. 따라서 $B$ 팀에게는 승리가 절실 한 경기여서 선수들의 긴장한 모습이 역력하다. 하지 만 마음이 쓰이는 건 $A$ 팀 선수들도 마찬가지이다. $B$ 팀 에는 어린 시절부터 함께 운동한 친한 선수들이 많기 때문이다. $A$ 팀 감독이 팀의 에이스인 $C$ 선수를 불러, "너는 팀의 에이스이니 이번 경기에 출전할지, 체력 관 리 차원에서 경기에 빠질지 네가 결정해라"고 지시한 다. $C$ 선수는 고민에 빠진다. 팀의 주축선수로서 큰 비 중을 차지하고 있고 개인 기록도 중요하지만, 자신이 출전하지 않게 되면 $B$ 팀이 경기에 이겨 4 강에 진출할 확률이 높아진다. 만약 당신이 $C$ 선수라면 어떤 선택을 하겠습니까?

위와 같은 구체적인 윤리적 상황을 애니메이션 영상으로 제시하고 심층면담을 진행한 결과, 앞선 설문 결과와 마찬 가지로 선수들의 윤리적 판단에 있어 인정주의가 강하게 작 용하는 것으로 나타났다.

“체력관리 한다는 핑계로 경기에 안 뛸 것 같아요. 좋은 핑계거리도 있고, 무엇보다 어린 시절부터 함께 운동하던 친구들이 소속된 팀이 해체되는 것은 막아야 하잔아요. 경기에 뛴다고 해도 친한 친구들이 신경 쓰여 최선을 다하기도 어려울 것 같아요" (배구선수, C)

“우리 팀은 이미 4강이 확정된 상황이고, 상대팀은 이번 경기에서 지면 팀이 해체되는 거라면, 당연히 안 뛰는 게 맞죠. 상대 선수들은 경기에 지면 진짜 앞으로 운동할 데가 없어지는 거잖아요. 어려울 때 돕는 게 그게 동료 아니에요? 어려운 상황에 처한 동료를 돕는 것 이 같이 운동하는 사람으로서 도리라고 생각해요" (태권도선수, F)

스포츠선수의 개인과 집단에 대한 관점이 윤리적 의사결 정에 어떻게 영향을 미치고 있는지 알아보기 위해 다음과 같 은 상황을 제시하였다.

6 명이 한 팀을 이루는 토론대회를 앞두고 $P$ 는 스피 치 능력이 뛰어나지는 않지만 자신의 능력을 개발하고 경력도 쌍기 위해 토론 팀에 합류하고자 한다. 하지만 자신의 부족한 실력 때문에 팀이 좋은 성적을 얻지 못 할 것을 고려해 참가하지 말아야 하는 것은 아닌지 고 민한다. 토론대회는 누구나 원하는 사람이면 참가할
수 있지만, 팀에 합류하기 위해서는 자신의 스피치 역 량이 뛰어나다고 다른 팀원들에게 거짓말을 해야 하는 상황이다. 당신이 P라면 어떤 선택을 할 것인가?

이 질문에 일반인의 $61.7 \%$ 가 '참가하겠다'고 응답하 며 팀에 피해를 끼칠 수 있지만 자신의 능력을 개발하고 경력을 쌍는 것도 중요하다는 개인중심 성향을 드러냈 다. 반면 스포츠선수는 $38.2 \%$ 만이 '참가하겠다' 고 답했 는데, 자신의 능력개발을 위해 팀 전체에 피해를 끼쳐서 는 안 된다며 상대적으로 집단중심 성향을 더 강하게 드 러냈다. 추가적인 질문으로, "윤리적으로 논쟁이 되는 문제에 있어 다수가 옳다고 결정하면 나의 생각과 다르 더라도 따르는 것이 맞다"라는 문항에 대해 일반인은 $48 \%$, 스포츠선수는 $78.3 \%$ 가 '그렇다'라고 답하여 옳고 그름의 판단 기준에 있어 집단주의 성향이 스포츠선수 들에게 더 강하게 반영되는 것을 확인할 수 있었다. 주 목할 부분은 이러한 강한 공동체의식이 집단 이기주의 경향으로 나타나기도 했다.

양심 없기로 이름난 사업가 P가 자신이 정부포상 행 사에서 대통령 훈장을 받게 되면 어려운 환경에 처해 있는 아이들을 지원할 수 있도록 당신이 근무하는 자 선단체에 기부금 200 억 원을 내놓겠다고 한다. 다만 $P$ 가 훈장을 받기 위해서는 자선단체에 소속된 직원들로 부터 추천을 받아야 한다. P가 훈장을 받으면 이것을 명분으로 사회에 피해를 끼치는 사업을 더 활발히 진 행할지도 모른다. 하지만 당신의 단체는 좋은 일을 할 수 있는 200 억 원의 기부금을 얻는다. 당신은 $P$ 를 추 천할 것인가?

이 질문에 대해 일반인은 $42.3 \%$ 가 '추천하겠다' 고 답 한 반면, 스포츠선수는 $57.8 \%$ 가 추천하겠다고 답하여 일반인에 비해 스포츠선수에게서 집단 이기주의 경향이 조금 더 높게 나타났다. 추가적인 질문으로, "직장 상사 가 음주운전을 하려는 것을 목격했다면 신고하겠습니 까?”라는 문항에 대해 일반인은 44\%가 '신고한다'고 답 했으나, 스포츠선수는 27.9\%만이 '신고한다'고 답했다. 신고하지 않는 이유에 대해서, 일반인은 '나에게 불이익 이 올 것 같아서' $60.4 \%$, ‘다른 사람의 일에 관여하고 싶 지 않아서' $28.9 \%$ 순으로 답변했고, 스포츠선수는 $73.3 \%$ 가 '나에게 불이익이 올 것 같아서'라는 이유를 들 
었다. 흥미로운 점은 "깊은 밤 통행하는 사람이나 차가 없는 한적한 도로라도 무단횡단을 하지 않는다”라는 문 항에 대해 일반인은 $32.7 \%$, 스포츠선수는 $62 \%$ 가 '그렇 다'라고 답하여 스포츠선수가 일반인보다 상대적으로 높은 준법의식 수준을 보인다는 것이다. 그럼에도 불구 하고 스포츠선수들은 집단의 이익 앞에서는 오히려 준법 성이 현저하게 떨어지는 이중적 의식구조를 갖고 있음을 발견할 수 있었다. Beak과 Galang(2011), Cho와 Lee(2006), Greenberger, Miceli와 Cohen(1987), Hofstede(2001)의 연구에 따르면, 집단주의가 강하게 작용하는 조직은 관계중심적 인간관이 우세하고, 집단 과 조화를 강조하며 의사결정에 있어 집단의 이익이 합 리성이나 효율성보다 우선하기 때문에 집단의 부정이나 부조리를 외부에 알리기보다는 은폐하는 경향이 강해 부 패가 발생할 가능성이 높다고 밝히고 있다.

"신고 안 해요. 만약에 팀 선배나 코치님이 음주운전하려는 걸 목격 했는데 제가 신고하면, 저 수영계에서 완전 왕따 될 걸요. 그래도 제 지인인데... 그래서 제가 좋을 게 뭐가 있어요. 그냥 음주운전 하는 걸 말리긴 할 것 같은데 신고는 절대 안 해요." (수영선수, A)

"신고를 하면, 누가 신고했는지 나중에 다 알게 되니까 신고 안 할 것 같아요. 제가 배신자가 되는 거잖아요. 결국 그 사람 자기 인생이 걸 린 문제니까, 전 못 본 척 할 것 같아요. 저로 인해서 그 사람 인생이 잘못되는 건 오히려 더 죄책감 느끼게 될 것 같아요." (육상선수, D)

'성공하기 위해서는 개인의 노력보다 인맥이나 배경이 더 중요하다고 생각한다'라는 문항에 대해 일반인은 $51.9 \%$, 스포츠선수는 $58.4 \%$ 가 '그렇다'라고 답했다. 많은 사람들이 스포츠는 우리사회 다른 어떤 분야보다 능력주의 가 실현되는 곳이라 여긴다. 하지만 예상과 달리 스포츠선 수들은 개인의 성실성보다 어떤 지도자, 어떤 팀, 어떤 배경 을 갖고 있는지가 선수로서 성공의 중요한 수단이라고 생각 하고 있으며, 스포츠계에 연고주의가 강하게 작용하고 있음 을 확인할 수 있었다. 스포츠선수의 연고주의 인식이 스포 츠계 내부고발이나 신고의식이 낮게 나타나는 것에도 영향 을 미치는 것으로 분석된다.

“한국사회에서 성공하기 위해서는 개인의 노력보다 인맥이나 배경 이 더중요하죠. 그런데 스포츠계는 더욱 심한 것 같습니다. 예를 들 어, 각 종목 중앙연맹에서 대표선수를 구성하잖아요. 그러면 대표
선수를 구성할 때 경기력향상위원회, 기술위원회 등이 열리거든요. 그럼 위원들은 대표선수 선발하면 누굴 뽑겠어요. 다 자기 라인의 선수들 뽑을 거 아니에요. 제가 위원이라도 그럴 것 같아요. 다 결국 인맥이죠. 아직까지는 그런 것 같아요." (육상선수, D)

"그래도 사회는 점점더 개인의 노력, 실력 등으로 평가하는 것 같아 요. 배경과 인맥으로 어느 정도까지는 올라갈 수 있다고 해도, 그 이 상 더 올라가기 위해서는 개인의 노력과 실력이 있어야 된다고 생각 하거든요. 하지만 스포츠계는 달라요. 무조건 인맥이나 배경이 더 중요합니다. 슬프지만 현실이에요. 제가 아무리 혼자 발버둥치고 노력해봤자 뒤에서 밀어주고 앞에서 끌어주는 사람 없으면 한계가 있습니다." (철인3종 선수, E)

'도덕적으로 살면 피해를 본다'라는 문항에 대해 일반 인은 $47.2 \%$, 스포츠선수는 $46.9 \%$ 가 '그렇다'라고 답하 여 두 집단이 비슷한 양상을 보였다. 두 집단 모두 우리 사회에 정의가 제대로 실현되지 않고 있다고 생각하는 것으로 해석된다. 그런데 흥미로운 점은 '스포츠선수가 윤리적이면 이득을 본다'라는 문항에 대해 일반인의 '그 렇다’ 라는 답변은 $79.4 \%$ 로 상당히 높게 나온 반면 스포 츠선수들은 57.6\%만이 '그렇다'라고 답했다. 이는 우리 사회에서는 도덕적인 사람이 충분한 대접을 못 받지만, 스포츠선수가 도덕성을 갖추면 그만큼의 대접과 보상을 받을 수 있다고 일반인들은 생각하는 것으로 해석된다. 하지만, 정작 스포츠선수들은 자신들의 도덕성과 선수 로서 혜택이나 성공의 관련성을 비교적 낮게 인식하고 있는 것으로 해석된다.

“솔직히 일반 대중들이나 스푸츠계 내부의 사람들도 어떤 선수의 인 성이 나쁜지, 좋은지 진실은 알 수가 없잖아요. 사람들이 보는 건, 결 국 경기력이나 실력을 보는 거잖아요. 제가타 종목의 정말 유명한 선 수룰 아는데, 솔직히 인성은 정말 별로 거든요. 근데, 실력이 있으니 TV에도 자주 나오고 일반 대중들에게 각광받고 있어요. 스포츠계에 서 성공하려면 도덕성, 인성보다는 무조건 경기력이에요. 경기력 안 좋은데 인성 좋다고 주목받는 일은 절대 없잖아요." (육상선수, D)

"사실 운동선수는 착하면 안돼요. 착한 선수는 나중에 은퇴 후에, 오 랜 시간이 흐른 후에나 돌아오는 게 있을지는 모르겠지만 아직까지 한국사회는, 특히 스포츠 현장에서는 착하면 안 되는 것 같아요. 자 기 것은 욕심내서 챙길 수도 있어야 하고요, 적당히 싸가지도 없고, 융통성도 있어야 스포츠에서는 살아남습니다." (농구선수, H)

“솔직히말해서 주위에 종목불문하고, 잘하는 선수치고 착한 선수 없 
습니다. 결국에 실속 다 차릴 줄 알고, 본인이다 알아서 본인건 챙겨 가고. 그리고 특히나경기장안에서는 착할 필요가 없어요 치열한경 쟁을 하는데, 내가착하면 이길 수가 없다고 생각해요. 솔직히잘하는 선수 중에 인성 자체가 좋은 선수는 못 본 것 같아요. 물론 착한 애들 도 있죠. 하지만 그 애들이 잘하는 선수는 아니에요." (수영선수, A)

'자신이 성장하는데 가장 큰 영향력을 미치는 사람은 누구입니까?'라는 질문에 일반인과 스포츠선수 모두 1 순위로 부모님을 지목했다. 흥미로운 점은 부모님 다음 으로 영향력이 있는 사람으로 일반인은 사회적으로 성 공한 인물이나 역사적 위인(26\%), 학교 선생님(9\%) 순 으로 선택했지만, 스포츠선수는 코치나 감독님(32\%), 선배선수(11\%) 순으로 나타났다. 스포츠선수에게 지도 자가 부모님만큼 영향력이 크다는 것은 스포츠계 윤리 의식 제고를 위한 교육의 방향이나 지도자와 관련된 정 책에 있어서도 주목할 만한 부분이다.

\section{결론}

우리는 일상생활에서 수많은 윤리적 문제에 부딪히며 살 아간다. 그렇다면 옳고 그름의 문제에 있어 우리의 의사결 정은 어떻게 내려지는 것일까? 우리는 윤리적 문제를 합리 적인 인지의 과정을 거쳐 처리하는 것일까, 아니면 숙고의 과정 없이 감정에 의해 즉각적으로 처리하는 것일까? 최근 도덕심리학이나 인지 신경과학 분야에서는 인간은 일상에 서 정서가 담겨진 직관에 의해 자동적이고 즉각적으로 판단 하고 행동한다는 주장이 지배적이다. 그렇다면 이러한 직관 은 어떻게 형성되는 것일까? Haidt(2001, 2007, 2008, 2012)는 성인의 옳고 그름에 대한 명제적 지식은 그가 어린 시절에 신체적, 정서적으로 경험한 관습이나 문화를 통해 형성된 것이라 주장한다. 이에 본고는 Haidt의 사회적 직관 주의를 이론적 토대로 스포츠선수의 윤리적 의사결정에 있 어 일반인과 차이점을 검토하고, 이러한 차이는 스포츠의 관습이나 규범 속에서 축적된 경험에 의해 형성된 정서적 직 관에 기인한다는 것을 실증적으로 규명함으로써 스포츠선 수의 정서적 직관에 영향을 주는 환경적 특성이 무엇인가를 식별하고자 하였다.

스포츠선수의 윤리적 판단 성향을 분석한 결과, 스포츠 선수와 일반인의 윤리적 판단 간에 통계적으로 의미 있는 차
이가 있는 것으로 나타났다. 이러한 차이를 분석하면 다섯 가지로 종합해 볼 수 있다. 먼저 스포츠선수는 일반적인 윤 리적 상황에서는 대체적으로 원칙을 강조하는 의무론적 윤 리관을 드러냈으나, 스포츠상황에서는 결과에 초점을 두고 판단하는 결과론적 윤리관을 매우 강하게 보이는 이중적 의 식구조를 나타냈다. 이는 스포츠가 규칙과 공정을 강조하기 에 스포츠선수의 의식에는 원칙의 중요성이 구조화되어 있 긴 하지만, 다른 한편으로 승리추구라는 스포츠의 본질적 가치를 어린 시절부터 내면화하고 있기에 스포츠상황에서 는 직관적으로 결과지향적인 판단을 내리는 것으로 해석할 수 있다. 둘째, 스포츠선수는 일반인에 비해 윤리를 당위규 범으로 인식하는 유교적 윤리관을 강하게 견지하고 있으며, 이로 인해 윤리적 의사결정에 있어 합리주의보다는 온정주 의가 비교적 강하게 작용하는 것으로 나타났다. 셋째, 스포 츠선수는 개인의 생각이나 이익보다는 타인의 생각과 집단 의 이익을 윤리적 의사결정에 있어 중요한 기준으로 여기고 있으며, 집단의 조화나 관계를 강조하는 집단중심 성향을 보였다. 그리고 이러한 강한 공동체의식은 때론 집단 이기 주의 양상으로 나타나기도 했다. 이러한 집단주의 성향은 연고주의를 조성하고 스포츠계의 내부고발이나 신고의식이 낮게 나타나는 데 작용하는 주요 원인으로 분석된다. 넷째, 일반인은 훌륭한 스포츠선수의 잣대를 뛰어난 실력과 그에 걸맞은 좋은 인성을 갖춘 선수로 인식하며 스포츠선수의 도 덕성을 중시여기는 반면, 정작 스포츠선수는 자신의 성공에 있어 도덕성의 영향과 그 중요성을 비교적 낮게 인식하고 있 었다. 끝으로 스포츠선수의 가치관 형성에 크게 영향을 미 치는 인물은 선수의 코치나 감독인 것으로 나타났다.

이처럼 유교적 가치관, 집단중심성향, 온정주의, 목표지 향성과 스포츠지도자의 영향력은 스포츠선수의 의식구조에 서 나타나는 두드러진 특징이라 할 수 있다. 따라서 스포츠 선수의 윤리적 직관을 구성하고 이를 형성하는 데 영향을 미 치는 요인 역시 이러한 맥락에서 고찰될 필요가 있다. 유교 적 가치관은 공동체 구성원 간의 조화, 신뢰성과 강한 유대 감을 바탕으로 공동체의식을 확립하여 사회를 발전시키는 동력이 되기도 하지만, 공동체의 이익에 우선적 가치를 부 여하는 집단주의 경향성과 옳고 그름의 문제에 있어 정의 (正義)보다는 의리의 가치에 치우치는 성향을 야기하기도 한다(Lee, 2008). 팀워크를 강조하는 스포츠문화 속에서 선 수들은 항상 자신을 억제하고 다른 동료들과 협동할 것이 권 장된다. 이러한 규범문화는 자연스럽게 선수들로 하여금 자 
신의 판단보다는 지도자와 팀 전체의 판단에 의존하려는 태 도를 조장하며, 이는 선수 개인의 주체성과 책임감을 약화 시키고 권위주의적 성향을 지니게 하는 데 영향을 미친다. 또한 '나(I)'보다는 '우리(we)'라는 의식과 '우리' 내의 관계 나 질서를 강조하는 분위기는 강한 연고주의를 조성하고, 이로 인해 선수들은 자신이 소속된 팀이나 운동부 내 부정과 불의에 대해 내적 갈등을 느끼지만 소속집단 내 권력과 직접 적으로 맞서는 것에는 회피하려는 경향이 있다.

인간은 대체적으로 자신이 속한 사회나 집단이 바람직하 다고 평가하는 것을 배우고 받아들이는 경향성이 있다 (Chu, 2020; Kahneman, 2011; Narvaez, 2014). 또한 자신이 속한 사회나 집단의 규범에 따라 행동하도록 배우 고, 그것을 자신의 것으로 내면화하는 과정을 통해 도덕적 직관이 형성된다(Haidt, 2012). 스포츠선수들의 윤리적 의 사결정에 있어 이중적 구조를 보이는 원인도 여기에서 찾아 볼 수 있는데, 이들의 윤리적 판단과 행동은 단지 개인의 윤 리적 결정에 의한 것이 아니라 스포츠 속 문화나 관습적 규 범에 의한 일종의 합의로 결정된 것일 수 있다. 왜냐하면 스 포츠 속 도덕원칙은 스포츠의 관습이나 가치를 반영하는 것 이므로 스포츠선수의 도덕적 판단은 그것에 순응하기 때문 이다. 하지만 여기서 주의해야 하는 것은 스포츠에서 수용 하는 도덕규범과 가치가 존재할 수 있지만, 그 도덕규범과 가치의 근간이 되는 도덕성의 근본원리는 일반사회의 도덕 적 관점에서 벗어나서는 안 된다는 것이다(Oh, et al., 2001). 왜냐하면 스포츠 경험을 통해 형성된 선수들의 윤리 적 직관이 일상에서 겪는 다양한 윤리적 상황들을 편향되게 해석하거나 도덕적인 상황으로 인지하지 못하는 방해요소 로 작용할 수 있기 때문이다. 달리 말해, 스포츠선수의 도덕 적 직관이 일반사회의 보편적 도덕규범과 부합하지 않으면 다른 사회 구성원들과 도덕적 공감을 형성하지 못하여 불필 요한 갈등을 겪을 수 있다.

스포츠선수의 윤리적 의사결정이 대부분 직관적인 형태 로 도출되며 이러한 윤리적 직관의 형성은 스포츠 속 규범문 화에 크게 영향을 받는다. 스포츠의 문화적 관습을 통해 형 성된 정서적 직관은 스포츠 집단 내의 도덕적 믿음으로 공유 되어 쉽게 바뀌지 않으며 그러한 믿음에 반하는 정보에 대해 서는 배타적인 태도를 취하는 경향이 나타난다. 따라서 스 포츠선수의 비윤리적 행동을 감소시키기 위해서는 선수의 비윤리적 행동과 스포츠 조직문화의 관련성을 탐색해야 한 다. 스포츠계 불미스러운 사건, 사고 발생 후 개인에 대한 징
벌과 규제에만 집중할 것이 아니라, 그러한 비윤리적 행동 을 억제할 수 있는 환경적 조건을 조성하도록 노력하는 것이 무엇보다 중요하다. 특히 오늘날 스포츠는 승리와 업적을 과도하게 강조하는 승리지상주의가 팽배해졌음을 고려할 때, 스포츠선수들의 성과에 대한 스트레스는 일상적이다. 이러한 강한 목표지향성은 결과론적 윤리관을 형성하고, 이 는 편향된 윤리적 의사결정에 영향을 미칠 뿐만 아니라 비윤 리적 행동을 합리화하는 요인으로 작용하기에 이를 억제할 수 있는 제도적 장치와 환경의 변화가 필요하다. 어떠한 환 경에서 형성된 직관인가에 따라 그 직관이 도덕적일 수도 있 고, 비도덕적일 수 있다. 따라서 스포츠선수들이 정서적 직 관을 윤리적으로 발달시킬 수 있는 바람직한 문화와 환경을 조성해야 한다.

대부분의 엘리트 스포츠선수들은 어린 시절부터 스포츠 를 통해 도덕적 규범과 예절을 배우고, 윤리적 문제를 숙고 하고 실천할 수 있는 경험을 축적한다. 이런 점에서 선수들 의 정서적 직관을 보다 도덕적으로 형성할 수 있도록 도울 수 있는 스포츠지도자의 역할이 매우 중요하다. 스포츠지도 자의 지도방식은 스포츠 속 가치나 규범의 내면화를 매개하 는 변수로서 스포츠선수의 성장 과정에서 도덕적 직관 형성 에 지대한 영향을 미치는 요인이다. 스포츠지도자의 역할과 지도방식이 선수들이 어떤 '사람'이 되느냐에 있어서 막대 한 영향을 미치는 요소로 간주되는 이유가 여기에 있다. 스 포츠지도자는 단순한 통제나 습관을 강조하는 일방적인 지 시형의 교육방법보다는 스포츠선수들이 윤리적 상황에 대 해 스스로 고민하고 합리적으로 추론할 수 있도록 쌍방향적 인 소통형 교수방법을 적극 활용하고 자율성과 주체성을 키 울 수 있는 분위기를 조성하는 것이 필요하다.

본 연구는 윤리적 의사결정에 있어 스포츠선수와 일반인 간의 뚜렷한 차이를 확인하였다. 그리고 이 차이는 어린 시 절부터 스포츠선수와 일반인이 경험하는 다른 문화적 배경 을 반영하는 것으로 볼 수 있다. 하지만 스포츠선수와 일반 인의 윤리적 판단 간의 차이에 대한 해석을 윤리의식 전체로 일반화하는 데는 주의가 요구된다. 스포츠선수의 윤리적 판 단 성향과 스포츠 속 문화적 특징을 간단한 설문문항이나 심 층면담을 통해 진단하는 데는 한계가 있다. 이러한 측면에 서 본 연구는 예비적이고 실험적인 연구에 그치지만, 추후 이 연구의 타당성을 검증하는 보다 심층적이고 다양한 후속 연구가 수반될 것으로 기대된다. 스포츠계의 윤리의식 제고 를 위해서는 스포츠 구성원의 윤리의식에 대한 심층적인 이 
해가 우선되어야 한다. 본 연구가 스포츠선수의 윤리의식을 사회문화적 맥락에서 접근하는 연구의 활성화에 촉매제 역 할을 할 수 있기를 기대한다.

\section{참고문헌}

Arnold, P. J. (1997). Sport, Ethics and Education. London: Cassell.

Baek, Y. J., \& Galang, M. C. (2011). The Effect of National Culture and Organizational Ethical Culture on Ethical Decision Making Process. Journal of Organization and Management, 35(4), 117-143.

Blair, R. J. (1995). A Cognitive Developmental Approach to Morality: Investigating the Psychopath. Cognition, 57(1), 1-29.

Brass, D. J., Butterfield, K. D., \& Skaggs, B. C. (1998). Relationship and Unethical Behavior: A Social Network Perspective. Academy of Management Review, 23, 14-31.

Caldwell, D. F,. \& Moberg, D. (2007). An Exploratory Investigation of the Effect of Ethical Culture in Activating Moral Imagination. Journal of Business Ethics, 73, 193-204.

Carr, D. (1998). What Moral Educational Significance has Physical Education? A Question in Need of Disambiguation. In M. J. McNamee \& S. J. Parry (Eds.), Ethics and Sport (pp. 119-133). London: E and FN Spon.

Cho, E. K., \& Lee, J. J. (2006). Analyzing the Corruption-inducing Elements of Nepotism Culture among Countries. Korean Public Administration Review, 40(4), 491-509.

Chu, B. W. (2020). An Analysis of the Relationship between Intuition and Reasoning in Moral Education: Focusing on Haidt \& Narvaez. Elementary Moral Education Journal, 68, 83-117

Damasio, A. R. (1994). Descartes'Error: Emotion, Reason, and the Human Brain. New York, NY: Putnam.

Durkheim, E. (2019). The Rules of Sociological Method. (B. Y. Yoon, Trans.). Seoul: Seamoolgyul (Original work published in 1895).

Greene, J. D. (2014). Beyond Point-and-shoot Morality: Why Cognitive (neuro) Science Matters for Ethics. Ethics,
124(4), 142-171.

Haidt, J. (2001). The Emotional Dog and Its Rational Tail: A Social Intuitionist Approach to Moral Judgment. Psychological Review, 108(4), 814-834.

Haidt, J. (2007). The New Synthesis in Moral Psychology. Science, 316(5827), 998-1002.

Haidt, J. (2008). Morality. Perspectives on Psychological Science, 3, 65-72.

Haidt, J. (2012). The righteous mind: Why good people are divided by politics and religion. NY: Pantheon Books.

Haidt, J., \& Graham, J. (2007). When Morality Opposes Justice: Conservatives Have Moral Intuitions that Liberals May not Recognize. Social Justice Research, 20(1), 98-116.

Hofstede, G. (2001). Culture's Consequences: Comparing Values, Behaviors, Institutions and Organizations Across Nations (2nd ed.). London: Sage.

Kahneman, D. (2011). Thinking Fast and Slow. New York: Brockman.

Kang, I. K. (2015). The Role of Moral Intuition and Moral Reasoning in Character Education. Korean Education Inquiry, 33(4), 73-97.

Koop, G. J. (2013). An Assessment of the Temporal Dynamics of Moral Decisions. Judgement and Decision Making, 8, 527-539.

Kuhn, D. (1991). The Skills of Argument. New York. NY: Cambridge University Press.

Lapsley, D. K., \& Power, F. (2005). Character Psychology and Character Education. Notre Dame, IN: University of Notre Dame Press.

Lee, J. H. (2008). The Effect of Parental Behavior within the Confucian Context on the Shaping of Moral Integrity. Korean Journal of Psychology, 27(3), 783-818.

Lee, J. R. (2017). Moral Intuition and Moral Education. Journal of Moral \& Ethics Education, 56, 109-138.

Lieberman, M. D. (2000). Intuition: A Social Cognitive Neuroscience Approach. Psychological Bulletin, 126(1), 109-137.

MacIntyre, A. (1984). After Virtue (2nd ed.). Notre Dame, IN: University of Notre Dame Press.

Moon, K. H. (2019). The Influence of Moral Intensity on Moral Decision Making. Elementary Moral Education Journal, 64, 1-31. 
Narvaez, D. (2010). Moral Complexity: The Fatal Attraction of Truthiness and the Importance of Mature Moral Functioning. Perspectives on Psychological Science, 5(2), 163-181.

Narvaez, D. (2014). Neurobiology and the Development of human morality: Evolution, Culture and Wisdom. New York: W. W. Norton.

Niebuhr, R. (2013). Moral Man and Immoral Society: A Study in Ethics and Politics. Louisville, KY: Westminster John Knox Press.

Oh, M. S., Doh, S. D., Park, C. K., \& Chu, B. W. (2001). A Comparative Study on Ethical Attitudes of Korean, Japanese and American. Korean Journal of Comparative Education, 11(1), 29-78.

Oyserman, D., \& Lee, S. W. S. (2008). Does Culture Influence What and How We Think? Effects of Priming Individualism and Collectivism. Psychological Bulletin, 134, 311-342.

Park, S. J., \& Im, H. J. (2011). Can Physical Education Class Contribute to Moral Education. Korean Journal of Sport Science, 22(4), 2481-2491.

Sage, G. (1988). Sport Participation as a Builder of Character?
The World and I, 3, 629-641.

Sage, G. (1990). Power and Ideology in American Sport: A Critical Perspective. Champaign, IL: Human Kinetics.

Shields, D. L., \& Bredemeier, B. L. (1995). Character Development and Physical Activity. Champaign, IL: Human Kinetics.

Shin, H. I. (2015). Individualism and Collectivism in Ethical Decision Making. The Korean Journal of Culture and Social Issues, 21(1), 67-96.

Slater, L. (2004). Opening Skinner's Box: Great Psychological Experiments of the Twentieth Century. New York: W. W. Norton.

Yang, H. S. (2016). J. Haidts Social Intuitionist Model and Its Implication for Moral Education. Journal of Moral \& Ethics Education, 53, 145-170.

Young, L., \& Durwin, A. J. (2013). Moral Realism as Moral Motivation: The Impact of Metaethics on Everyday Decision-making. Journal of Experimental Social Psychology, 49, 302-306.

Zajonc. R. B. (1980). Feeling and Thinking: Preferences Need No Inferences. American psychologist, 35(2), 151-175. 


\title{
스포츠선수의 윤리적 의사결정과 환경적 특성
}

\author{
임다연 ${ }^{1}$, 박성주 $^{2}$ \\ ${ }^{1}$ 국민대학교 강사 \\ 2국민대학교 교수
}

[목적] 이 연구는 Haidt의 사회적 직관주의 이론(social-intuitionist theory)을 토대로 스포츠선수와 일반인 의 윤리적 의사결정에 있어 차이점을 분석함으로써 스포츠선수의 윤리적 판단 성향을 이해하고 판단에 영향을 미치는 요인을 환경적 특성 측면에서 고찰하였다. 이를 통해 스포츠선수의 윤리의식 제고를 위한 교육의 방향 과 제도적 방안마련에 대한 시사점을 제공하는 데 연구의 목적이 있다. [방법] 이러한 연구목적을 위해 대한체 육회에 10년 이상 운동선수로 등록된 20대 엘리트선수 200명과 서울에 소재하고 있는 5개 대학교에서 200명의 20 대 대학생을 비교 대상으로 선정하였다. 문항별 반응경향은 백분율을 통해 조사되었으며, 엘리트선수 8 명의 심층면담을 통한 질적 데이터가 분석되었다. [결과] 연구결과는 다음과 같다. 첫째, 스포츠선수는 일반적인 윤 리적 상황에서는 대체적으로 원칙을 강조하는 의무론적 윤리관을 드러냈으나 스포츠상황에서는 결과에 비중을 두고 판단하는 결과론적 윤리관을 매우 강하게 보이는 이중적 의식구조를 나타냈다. 둘째, 스포츠선수는 일반 인에 비해 윤리를 당위규범으로 인식하는 유교적 윤리관을 강하게 견지하고 있으며, 이로 인해 윤리적 의사결 정에 있어 합리주의보다는 온정주의가 비교적 강하게 작용하는 것으로 나타났다. 셋째, 스포츠선수는 개인의 생각이나 이익보다는 타인의 생각과 집단의 이익을 윤리적 의사결정에 있어 중요한 기준으로 여기고 있으며, 집단의 조화나 관계를 강조하는 집단중심 성향을 보였다. 넷째, 일반인은 훌륭한 스포츠선수의 잣대를 뛰어난 실력과 그에 걸맞은 좋은 인성을 갖춘 선수로 인식하며 스포츠선수의 도덕성을 중시여기는 반면, 정작 스포츠 선수는 자신의 성공에 있어 도덕성의 영향과 그 중요성을 비교적 낮게 인식하고 있었다. 끝으로 스포츠선수의 가치관 형성에 크게 영향을 미치는 인물은 선수의 코치나 감독인 것으로 나타났다. [결론] 스포츠계의 윤리의식 제고를 위해서는 스포츠 구성원의 윤리의식에 대한 심층적인 이해가 우선되어야 한다. 본 연구가 스포츠선수의 윤리의식을 사회문화적 맥락에서 접근하는 연구의 활성화에 촉매제 역할을 할 수 있기를 기대한다.

주요어: 스포츠선수, 윤리적 의사결정, 윤리의식, 추론, 직관 